\title{
Perceptions of Students with Disabilities on Reasonable Accommodation at a Tertiary Education: A Case of a Rural University in Limpopo Province, South Africa
}

\author{
M.H. Mukwevho ${ }^{1, *}$ and A. Gadisi ${ }^{2}$ \\ ${ }^{1}$ Faculty of Humanities, Social Sciences, and Education, University of Venda, Thohoyandou 0950, South \\ Africa \\ ${ }^{2}$ Disability Unit, University of Venda, South Africa
}

\begin{abstract}
The advent of democracy in South Africa has put initiatives to redress social injustice suffered by women and people with disabilities. Enrollment of students with disabilities at universities increases yearly, influencing an increase in buying of assistive technologies to enable a teaching and learning environment.

This paper explores the perceptions of students with disabilities on the role of reasonable accommodation in terms of accessibility and facilitation of teaching and learning at the university based on the human rights approach. A pre-corvid 19 pandemic survey used a convergent parallel mixed-method design to evaluate perceptions of reasonable accommodation on the campus. Both quantitative and qualitative data were collected roughly simultaneously and integrated into the interpretation of the overall results. A focus group comprised of the representatives of students with disabilities was interviewed. The surveyed population comprised all students with disabilities between the ages of 18 to 25 registered with the Disability Support Unit (DSU) of the University of Venda. The questionnaires collected reasonable accommodation perceptions and satisfaction rates from students about organizational support and training. The distributed questionnaires produced a $90 \%$ response rate. The findings highlighted that students with disabilities encountered barriers of inaccessibility to classrooms and residents. Adequate learning material is a barrier for students with visual disabilities. Institutional budget and item costs render buying assistive technologies and building new infrastructures for students with disabilities a constraint. Policy and practice in the institution remain a limitation to interfacing education and disability smoothly.
\end{abstract}

Keywords: Accessibility, accommodation, disability, gender barriers, marginalized, perceptions.

\section{INTRODUCTION}

The prevalence of disability in South Africa is $7.5 \%$ [1]. The rate of disability prevalence is high amongst females than males at $8.5 \%$ and $6.5 \%$, respectively. Prevalence of disability per age group is as follows; $15-$ 19 years is $2.6 \%$; $20-24$ years is $2.4 \%$; $25-29$ years is $2.5 \%$. White Paper on the Rights of Person with Disabilities (WPRPD) [2] propagates the removal of barriers to access and participation as well as protecting the rights of persons at risk of compounded marginalization. Gender equality in education overlooks the added problem faced by students with disabilities [3]. This paper proposes to focus on the situation/condition of students with disabilities within a South African tertiary institution. A reasonable accommodation proposed in this paper relates to change in ways things are usually done for the provision of equal opportunities/treatments for students with disabilities. It implies that the auxiliary aids and services offered are effectively compatible to meet the needs of students with disabilities. The incidents of females with disability [1] are among the marginalized

*Address correspondence to this author at the Faculty of Humanities, Social Sciences, and Education, University of Venda, Thohoyandou 0950, South Africa; Tel: +2715 962 8529; E-mail: harry.mukwevho@univen.ac.za in society whose needs to equal participation is neglected in educational discourse. More females than males attend tertiary education [1], and that $1 / 5$ are individuals with severe difficulties. The population group with the highest access rate at the tertiary level was found to be whites, whereas black Africans form the lowest category.

In Canada, the Ontario Human Rights Commission [3] found that barriers to education for students with disabilities occur because of failure by an education provider to make available needed accommodation promptly. Some barriers relate to inadequate funding based on budgetary considerations done without the actual needs assessment of students with disabilities. In some instances, physical inaccessibility is evident through the lack of ramps and /or elevators in multilevel school buildings. Accommodation roles and processes are found wanting by being not provided on time, insufficiently, or not provided at all.

Disability is a diverse group with gender identity and different socio-economic statuses. D'Andrea [4] argues that, even though the enrolment of students with disabilities has increased in the higher education of South Africa, there is a high rate of inaccessibility in the learning environment, especially for physical and visual 
impaired students. Visual impaired students find it difficult to integrate into the learning environments due to academic and social barriers [5]. Limited access to information made it difficult for disabled students to demonstrate academic knowledge in standardized tests. Social barriers include bullying from other students; academic barriers include the inability to access the institutional buildings for the learning environment. Some buildings are fragmented, making them inaccessible for physically impaired students [3]. Consequently, students with disabilities are not accorded the social rights as other people in society. Inclusive education, which propagates to cater for people with disabilities to participate effectively in a free society, is unlikely to materialize. Man-made barriers still hinder students with disabilities' opportunities to access knowledge freely at the tertiary level. At tertiary institutions, students with disabilities have moved from a protective environment in which personnel is legally responsible for identifying and providing appropriate services to an environment in which the students selfidentify with a disability and request specific accommodations with the disability unit. Rugoho and Maphosa [6] argued that females face the typical disadvantages of gender inequality because they are not given the opportunity to learn about sexual and reproductive health compared with their peers due to prejudice and perceptions to be non-sexual.

Research Brief on Disability and Equality in South Africa [6] contend that most universities do not consider the needs of students with disabilities in the formulations of language policies or residence placement policies. Reasonable accommodation conditions remained a challenge to many students with disabilities in historically disadvantaged institutions of high learning in South Africa. Some premises within the institution do not provide for physical and visually impaired people and are pedestrian-oriented [7]. Many students with disabilities have difficulties in accessing heavy doors of their residences and some lecturing venues. The lecture room's setting arrangements still have podiums and boards inaccessible or far away to physical and visually impaired students. The sitting arrangements provide little spaces that are inaccessible for students using wheelchairs. A reasonable accommodation is still viewed as an individual problem rather than an environmental one. Access to education represents a barrier evidenced by a lack of visibility and voice of students with disabilities in the position of authority. The study [7] focused on challenges faced by staff serving students with disabilities in a historically disadvantaged tertiary institution, such as lack of resources, lack of funding, and the disproportionate ratio of staff to students. On the other hand, this paper seeks to evaluate perceptions and practices prevailing in addressing the plight of a diverse group of students with disabilities at different educational levels in terms of providing reasonable accommodation conditions in the tertiary institution.

In South Africa, the Bill of Rights, Chapter 2 of the Constitution, states that everyone has the right to basic education, including adult basic education. It has created the opportunity to address the inequalities experienced during apartheid. The new dispensation provides for all types of disabilities to enjoy fundamental freedom on an equal basis and areas where adaptations must be identified to enable people with disabilities to exercise their rights effectively. Taormina-Weiss [8] asserts that the cost of marginalizing people with disabilities is very high not only for family members but also for the public. Marginalization makes people with disability to be dependent upon society that exclude them in many areas of social participation. People with disabilities should be free to pursue active lives complete with social interactions, and society would benefit greatly. Limited resources and facilities in institutions of higher learning made it possible only to accommodate a limited number of students with disabilities, such as blind students, partially sighted, and physically challenged students. The limited resources could be a shortage of Braille system, tape recorder, writer, shortage of computer and audio-visual devices.

Disability Support Units in South African universities offer assistive services such as screen readers, Braille system, audiobooks and journals, special typewriters for the blind, and extra time for tests and examinations, but the barriers to academic curricula, physical environment, teaching and learning support, allocation, and distribution of resources to the disabled remains a daunting task to overcome [9]. The Disability Unit is responsible for organizing structural adjustments to enable students with disabilities to attend classes and find alternative ways to make curricula accessible. Not all universities in South Africa can provide disability services effectively because of being historically disadvantaged in terms of financial and human resources. Plan International [10] argues that girls experience discrimination and vulnerability because of gender and disability. Hence, there is a need to understand lived experiences and challenges faced in 
the lecture rooms and campus environment impacting students' performance with disabilities.

The Three Formulations of the Nexus Requirement [11] assert that reasonable accommodation is an alteration to some elements of the status quo that are intended to enable a person with a disability to participate in higher education, residential living, or public life to the same extent as the non-disabled. The changes may include the physical environment, time schedules, adjustments of requirements and policies, provision of assistive devices, and commuting related to accommodations. The study by Clarke and Sawyer [12] views a disability as an impairment that substantially limits one or more life activities and that its range of possible accommodation is limited by human imagination. Disability support services vary across universities as a function of the number and quality of staff and the scope of services provided [13]. Barriers cited by students on [13] are the attitude of faculty and staff who are not familiar with disability challenges, access to textbooks in alternative formats, and student advocacy skills.

Taylor, Turnbull, Bleasdale, Francis, and Forsyth [14] posit that students with disabilities in the United Kingdom face different barriers to higher education concerning learning activities in certain courses. The difficulties faced related to assessment activities include difficulties reading examination papers or writing answers or difficulties engaging in social aspects such as disclosing their needs. Hence, the United Kingdom Equality Act 2010 [3] requires reasonable adjustments to be made to the curriculum, pedagogy, and assessment for students with disabilities to avoid discriminatory practices. However, to claim this right to such an adjustment, a prospective student must be able to demonstrate that he or she is disabled.

Per [13], when the disabled student registers at university, or at some point during their studies at university, he or she needs to provide medical evidence or undergo some form of assessment so that appropriate adjustments can be put in place. Such adjustments will typically be documented in some form of the individual student learning plan. Hidden disabilities account for most students disclosing a disability as they enter higher education. Ingeno [15] advocates that reasonable accommodation should not have to wait until someone comes and self-identifies, but rather equal access needs to be possible and implementable from the beginning.
In Australia, equity in quality learning bodes well for students with disabilities, but barriers continue to hinder the realization of these goals [16]. There is an increase in the number of students with hidden disabilities unrecognized by many university staff. Disabilities cited in this regard include specific learning disabilities, attention-deficit/hyperactivity disorder (ADHD), and autism spectrum disorder (ASD). In (15), if a student does not reveal an impairment "in sufficient detail to allow an institution to respond to it", the institution is not obligated to adjust under the discrimination act.

Fleming, Oertle, and Plotner [17] assert that services available to students with disabilities are unclear, unknown by many, and underutilized. This is exacerbated by a lack of a closer working relationship between staff in DSU and other campus services such as career or counseling centers. It is difficult to know what kind of help disabled students can get on campus in some instances. In (16), the increase in visibility of offices of disability resources through the increase of university staff who are aware of disability resources is necessary. On the other hand, De Los Santos, Kupezynski, and Mundy [18] argued that higher education institutions should reorganize support services to meet a multitude of needs for students with disabilities. The question remained that of ascertaining to what extent is the support service provided by university management fulfills the objectives and situations of the students.

Hence, the objective of the study sought to evaluate how students with disabilities were assisted in achieving reasonable accommodation conditions at different educational levels in the campus through organizational and academic support. The following hypotheses were used:

Hypothesis 1: Instructors use different methods for teaching content and alternative ways for students with disabilities to participate in-class activities (auxiliary aids).

Hypothesis 2: All students experience campus fully and equally by utilizing the same practices through reasonable accommodation efforts.

\section{The Rationale of the Hypotheses}

The rationale for creating accessible spaces and course content on the campus is to ensure that students with disabilities are encouraged to discuss the accommodation with instructors in assisting in creating a supportive environment. Teaching is made 
accessible to all students through all modalities such as sign language, seeing, and touching to break down discrimination and stereotypes leveled against disability and special education needs.

\section{The Rationale for Students with Disabilities to Enjoy Reasonable Accommodation Conditions}

The rationale for the hypothesis is to ensure that ongoing development that provides an inclusive environment also embraces and celebrates diversity. Barriers for students with disabilities in terms of inclusion and other range of characteristics, such as policies, practices, and procedures, should regularly be reviewed and removed where possible. People with a disability should be visible on campus in positions of power and authority (administrators, student leaders, and faculty officers). Reasonable accommodation efforts should promote social integration.

\section{Theoretical Perspective}

This paper followed a Social Model of disability, human rights, and development propagated by Albert [19]. It is a radical alternative to the individualized medical conception of disability, asserting that people with disabilities are disadvantaged not because of their impairments but because of the limitations imposed by social, cultural, economic, and environmental barriers.

Disability, in this regard, is not about health or pathology but discrimination and social exclusion. Unlike the medical model assumption of individual abnormality and the primacy of cure, the social model implicitly acknowledges the normality of impairment while not rejecting intervention. Medical advances have so far reduced the number of people with disabilities and lead to an increase, as people not only live longer but are also better able to survive illness and injury. Hence, the removal of disabling barriers, as well as a strong emphasis on human and civil rights, could put people with disabilities in the driving seat of their destiny.

By considering impairment as an ordinary part of life, the social model attempts to extract disability from the medicalized and special needs people and push for the mainstreaming of disability concerns in all developmental policies and practices. This model brings people with disabilities together in a common struggle for equality and rights. People with disabilities should be actors in their own lives rather than passive recipients of care. Putting people with a disability into the roles that could control and lead their lives offers a powerful device to liberating those who remain the poorest of the poor in all countryside. A human rights approach offers a societal transformation and a way for people with disabilities to transform their sense of whom they are- from stigmatized objects of care to values subjecting their own lives.

\section{MATERIALS AND METHODS}

The first phase of a survey was conducted with the students with disabilities $(N=110)$ to establish the extent of efforts made to reasonable accommodation in terms of academic and organizational support in the institution. The second phase focused on soliciting data through interviews with a focus group of students with disabilities $(\mathrm{N}=7)$ to establish the satisfaction rate in terms of reasonable accommodation efforts preferred by the disabled students.

\section{Participants}

The population consisted of $(\mathrm{N}=110)$ registered students with the Disability Support Unit (DSU) of the University of Venda. The self-administered questionnaires distributed produced a response rate of $90 \%$. Participants were from age 18 to 35 years old, comprised of 49 males and 51 females. The rationale to conduct the survey design was based on the economy of the design and rapid turnaround in data collection. Questions addressed hearing, learning disabilities, motor and visual impairment in terms of academic and organizational support.

\section{Instruments}

The self-administered questionnaires with a Likert scale for closed-ended questions were used. The Linkert scale questions addressing academic support were depicted by choosing one of the following (not offered; offered less than $25 \%$ of the time; offered $25 \%$ to $50 \%$ of the time; offered $51 \%$ to $75 \%$ of the time; offered more than $75 \%$ of the time). The questions addressing organizational support ranged from (not used; used less than $25 \%$ of the time; used $25 \%$ to $50 \%$ of the time; used $51 \%$ to $75 \%$ of the time to use more than $75 \%$ of the time. The semi-structured questions were used as an interview guide for the focus group. The satisfaction rate measured the reasonable accommodation in terms of academic and organizational support. The instrument was pre-tested on a sample of different groups of disabled students. It was used to measure the needs for accommodation and satisfaction rates about support services. A focus 
group discussion comprised partially sighted, blind, students with Albinism, and physically disabled.

\section{Ethical Consideration}

Permission to conduct the research was sought from the Disability Support Unit. Participants were briefed on the nature and scope of the study. Participants in the focus group discussion and those who completed the questionnaire were assured of voluntary participation, confidentiality and that their identities will remain anonymous.

\section{Procedure}

The data collection process occurred over the fourweek window period. The participants completed the questionnaire addressing the subjective well-being rating and satisfaction with the accommodation. Before data analysis, a survey was reviewed for missing data. In the case where a survey contained two or more missing items, the questionnaire was not considered for analysis. The quantitative and qualitative data were analyzed separately such that quantitative results were used to plan the qualitative follow-up.

\section{Data Analysis}

Analysis of data was descriptive and inferential statistics. Descriptive statistics were presented to profile the demographic characteristics, and inferential statistics were performed to investigate relations between variables. IBM SPSS version 25 was used for data analysis. The preliminary analyses, such as the normality test, were done to make sure there was no violation of the assumptions. An ANOVA was conducted to verify whether reasonable accommodation and social integration of the sample differ based on educational level. The Pearson product-moment correlation test was done as a follow-up to examine the relationship between accommodation, perception, and social integration. Based on the mean and standard deviation of these variables, a satisfactory rate was determined.

\section{RESULTS}

We performed a descriptive statistic to profile our participants, as illustrated in the tables below. The age variable was categorized into 2 , i.e., the 18 to 25 years and 26 to 35 years. Regarding gender, only two categories were used (female and male). At the same time, the levels of education were $1^{\text {st }}$ year of university as $1^{\text {st }}$ level, second year as $2^{\text {nd }}$ level, third year as $3^{\text {rd }}$ level, and fourth year as honors level. The participants were coming from 7 provinces, as indicated in the tables.

As illustrated in Table 1, the age group $18-25$ constitutes $99 \%$ of the sample whilst 26 - 35 years account for $1 \%$ of the participants. Many participants on the campus are below the age of 25 years. Females

Table 1: Demographic Profiling of Participants

\begin{tabular}{|c|c|c|c|}
\hline Variable & Category & Frequency & Percentage \\
\hline \multirow[t]{2}{*}{ Age } & $18-25$ years & 99 & $99 \%$ \\
\hline & $26-35$ years & 1 & $1 \%$ \\
\hline \multirow[t]{2}{*}{ Gender } & Female & 51 & $51 \%$ \\
\hline & Male & 49 & $49 \%$ \\
\hline \multirow[t]{5}{*}{ Level of education } & The first year of university & 17 & $17 \%$ \\
\hline & The second year of university & 26 & $26 \%$ \\
\hline & The third year of university & 44 & $44 \%$ \\
\hline & Fourth-year of university & 12 & $12 \%$ \\
\hline & Masters & 1 & $1 \%$ \\
\hline \multirow[t]{7}{*}{ Province } & Eastern Cape & 2 & $2.0 \%$ \\
\hline & Free State & 3 & $3.0 \%$ \\
\hline & Gauteng & 7 & $7.0 \%$ \\
\hline & KwaZulu Natal & 9 & $9.0 \%$ \\
\hline & Limpopo & 64 & 64.0 \\
\hline & Mpumalanga & 14 & $14.0 \%$ \\
\hline & North West & 1 & $1.0 \%$ \\
\hline
\end{tabular}


Table 2: Correlation between Organizational Support, Social Integration, and Reasonable Accommodation ( $\mathrm{N}=100)$

\begin{tabular}{|c|c|c|c|c|}
\hline & & Organizational support & $\begin{array}{c}\text { Social } \\
\text { integration }\end{array}$ & Reasonable accommodation \\
\hline \multirow[t]{2}{*}{ Organizational support } & Pearson Correlation & 1 & 0.048 & $0.464^{* *}$ \\
\hline & Sig. (2-tailed) & & 0.633 & 0.000 \\
\hline \multirow[t]{2}{*}{ Social Integration } & Pearson Correlation & 0.048 & 1 & 0.011 \\
\hline & Sig. (2-tailed) & 0.633 & & 0.916 \\
\hline \multirow{2}{*}{$\begin{array}{c}\text { Reasonable } \\
\text { Accommodation }\end{array}$} & Pearson Correlation & $0.464^{* *}$ & 0.011 & 1 \\
\hline & Sig. (2-tailed) & 0.000 & 0.916 & \\
\hline
\end{tabular}

**. Correlation is significant at the 0.01 level (2-tailed).

participants were $51 \%$, whilst males accounted for $49 \%$. The results indicate that majority of the participants living on campus are females. Many students (44\%) are doing a third-year level, while $26 \%$ are on a second-year level. Close to $17 \%$ are enrolled at the first-year level, while $12 \%$ are doing the fourth year, and only $1 \%$ are enrolled at the master's level at the university. Many students form an undergraduate category, which collectively amounts to $83 \%$, whilst postgraduates constitute only $13 \%$. The majority (64\%) of the participants are from the Province of Limpopo, followed by Mpumalanga, accounting for $14 \%$ of the participants. Additionally, participants who hail from KwaZulu Natal made 9\%, Gauteng made 7\%, Free State made $3 \%$, Eastern Cape made $2 \%$, and North West made $1 \%$ of the entire sample.

An evaluation of the linear relationship between Organisational support, Social integration, and reasonable accommodation was measured using the Pearson correlation, as shown in Table 2.

The Pearson's correlation was performed in Table 2 to examine the association between organizational support, social integration, and reasonable accommodation. Pearson's correlation for organizational support and social integration was 0.048 with a $p$-value of 0.63 , indicating almost no relationship, and the results are statistically insignificant. Therefore, we can conclude that changes in organizational support do not tend to change levels of social integration. Although students with disabilities are provided with assistive devices and training in their use, the usage rate remains less than $50 \%$.

Any analysis using Pearson's correlation coefficient indicated that there is a mild positive relationship between organizational support and reasonable accommodation since the coefficient was 0.464 with a $\mathrm{p}$-value less than 0.05 . The results indicate that high levels of organizational support are associated with high levels of reasonable accommodation.

Although students receive organizational support, it does not sufficiently translate into effective education acquisition due to accommodation constraints. The Pearson's correlation between social integration and reasonable accommodation was 0.011 with a $p$-value of 0.916, implying a statistically insignificant relationship between social integration and reasonable accommodation. The result shows that changes in social integration are not necessarily associated with changes in reasonable accommodation.

Hypothesis 1: Instructors use different methods for teaching content and alternative ways for students with disabilities to participate in-class activities (auxiliary aids). A descriptive statistic shown in the table (Hypothesis 1) indicates.

All the participants $(100 \%)$ considered the accommodation efforts by the institutional resource allocation as reasonable, although not rated highly. However, regarding social integration, all the participants revealed that none of the listed accommodations efforts related to sign language, realtime captioning, oral interpreter, or transliterates were used. Considerable organizational support was offered; this is supported by $67 \%$ of the participants who stated that the organizational support was offered $25 \%$ to $50 \%$ of the time, whereas $31 \%$ of the participants believed support was offered less than $25 \%$ of the time. Only $2 \%$ mentioned that support was not offered at all.

Hypothesis 2: All students experience campus fully and equally through the utilization of the same practices through accommodation

A one-way ANOVA is conducted to test this hypothesis to determine if there were significant 


\section{Hypothesis 1: A Descriptive Statistic}

\begin{tabular}{|c|c|c|c|}
\hline Construct & Category & Frequency & Percent \\
\hline \multirow[t]{5}{*}{ Organization Support } & Not offered & 2 & 2 \\
\hline & Offered less than $25 \%$ of the time & 31 & 31 \\
\hline & Offered $25 \%$ to $50 \%$ of the time & 67 & 67 \\
\hline & Offered $51 \%$ to $75 \%$ of the time & 0 & 0 \\
\hline & Offered more than $75 \%$ of the time & 0 & 0 \\
\hline \multirow[t]{5}{*}{ Social integration } & Not used & 100 & 100 \\
\hline & Used less than $25 \%$ of the time & 0 & 0 \\
\hline & Used $25 \%$ to $50 \%$ of the time & 0 & 0 \\
\hline & Used $51 \%$ to $75 \%$ of the time & 0 & 0 \\
\hline & Used more than $75 \%$ of the time & 0 & 0 \\
\hline \multirow[t]{2}{*}{ Reasonable Accommodation } & Yes & 100 & 100 \\
\hline & No & 0 & 0 \\
\hline
\end{tabular}

differences in Organization support and educational levels, Social integration and educational levels, and Reasonable accommodation and educational levels. Educational level was used as the independent variable, while organizational support, social integration, and reasonable accommodation were dependent.

Analysis of variable results for the academic support, social integration, and reasonable accommodation was measured on an educational level. The preliminary analyses were done to check that there are no apparent violations of assumptions. Then an ANOVA was conducted to verify whether reasonable accommodation, social integration, and organizational support of the sample differ as a function of educational level. Educational levels were categorized into " 1 st $y e a r$ ", " 2 nd $y e a r$ ". " 3 rd $y e a r "$, and " 4 th year", "Honours", and "Masters" (Table 3).

A one-way ANOVA found that organization support significantly differs across the educational levels $F(4,95)=3.3, \quad p=0.014$, which implies that some instructors use different methods for teaching content. In addition, they seek alternative ways for students with disabilities to participate in-class activities. Nevertheless, the nature and rate of organizational support differ with educational levels.

Regarding Social integration, a one-way ANOVA found significant differences across educational level $F(4,25)=3.413, p=0.012$, which indicates that social integration differs based on educational level. Therefore, we can conclude that social integration is not good at some level of education.

Relating to reasonable accommodation according to educational level, the ANOVA test shows that $F(4,25)=2.538, p=0.045$. This implies that the reasonable accommodation perception significantly differs with educational levels. Hence, we can conclude that reasonable accommodation is evident in some levels of education, but not all.

Excerpts from group interview: Focus group discussion concerning accommodation

Table 3: ANOVA Test for Organizational Support, Social Integration, and Reason Accommodation

\begin{tabular}{|c|c|c|c|c|c|c|}
\hline & & Sum of Squares & df & Mean Square & $\mathbf{F}$ & Sig. \\
\hline Organizational support & Between Groups & 0.146 & 4 & 0.037 & 3.300 & 0.014 \\
\hline \multirow[t]{2}{*}{ Social Integration } & Between Groups & 0.025 & 4 & 0.006 & \multirow{2}{*}{3.413} & \multirow{2}{*}{0.012} \\
\hline & Within Groups & 0.177 & 95 & 0.002 & & \\
\hline Reasonable Accommodation & Within Groups & 8.919 & 95 & 0.094 & 2.533 & 0.045 \\
\hline
\end{tabular}


The representative of blind students had this to say: "There are no constructed sheltered paths to protect us during rainy days whilst attending classes".

Physically disabled student representative had this to say: "Some classes are inaccessible during rainy days due to mud and unpaved pathway".

The blind student representative reiterated and had this to say: "We are seldom notified of new constructions that could obstruct our movement on the campus. Furthermore, the journey to the library and classrooms have cars and buses because of the absence of secluded pedestrian paths".

The physically disabled representative had this to say: "Few places that have adapted toilets are Disability Support Unit and residence occupied by disabled students. The rest are old buildings which need to be renovated to comply with our plight".

The general concerns regarding residents were that many students with disabilities stayed on the ground floor with,

- no privacy,

- no security,

- few or no warden patrol to monitor the buildings,

- absence of lift or lifts not working,

- no adapted showers to cater to different disabled people.

Academic support to students with disabilities lags due to resources constraints. Many courses offered, including pure sciences, are not suitable for blind students. In this regard, tutors are expected to assist the students with disabilities where the lecturers have failed. Policies depicting behavioral expectations and compliance are available. However, the implementation of such programs is slow.

\section{DISCUSSION}

The study showed that reasonable accommodation at tertiary institutions remains a challenge to meet the diverse student body with a multitude of needs. Disability Support Unit, administrators, and academic staff are pressured to meet diverse student needs where resource constraints are apparent. Although alternative ways or methods to address the plight of students with disabilities are used, such measures still do not adequately accommodate disable groups to experience the campus environment fully and socially integrated. It concurs with $[4,5,9]$ assertion that students with disabilities are not accorded social rights as other students on the campus; and that they have limited access to information that could assist in asserting their potential and abilities. Consequently, this defeats the end of full inclusion and accommodation.

The paper supports the researches conducted in the field and shows how perceptions of accommodation affect the academic environment for students with disabilities in tertiary institutions. It links with [7] assertion that the absence of reasonable accommodation is a barrier in providing visibility and voice for students with disabilities. Focus group response regarding the inability to access classes during rainy days exposes the environment in which students with disabilities found themselves. All the hypotheses revealed perceptions of accommodation shortcomings in shaping academic performance at tertiary education.

The students felt not supported by institutions despite the new education environment's potential to support greater participation. Many barriers still exist. The students with disabilities are still being told that the institution is not equipped to provide them with the necessary support they require. Curriculum inflexibility and resource constraints regarding the manner it has been conceptualized remain the key barrier to the equitable participation of students with disabilities and their human rights [18].

Although Disability Support Unit has a policy that seeks to provide reasonable accommodations such as changing term papers and extending examination sessions, changes to the sitting environment of a class to adaptive technology (such as note-takers, recording devices, and readers for personal use), efforts made do not reasonably accommodate the disability diverse needs due to resource constraints. The physical and social environment for students with disabilities is not adjusted sufficiently to accommodate the quality of outcomes. Furthermore, students with disabilities are expected to compete at the level of non-disabled peers, which is unethical and unachievable in such a social and systematic environment of inequalities.

\section{CONCLUSION}

Although students with disabilities could access the institution of high learning, it does not imply free full participation and reasonable accommodation in the 
learning environment. Physical disabled and visually impaired students are affected by the physical environment set-up. Diversity of students with disabilities expose the inefficiency and ineffectiveness of institution in addressing their plight. There are still some gaps between policy and practice to streamline functions of academic staff with non-academic staff. Hence, IT specialists and mobility instructors should be enlisted to accommodate the students' interests with disabilities. Different categories of disabilities should be accommodated separately to observe human rights principles in institutions of high learning. The social difficulties described in this paper limits the important part of social connectedness and the ability to relate to others.

\section{DISCLAIMER}

The views expressed through this article are those of the individual authors writing in their capacities onlyand not those of their respective employers. The authors declare that they have no financial or personal relationships that may have inappropriately influenced them in writing this article.

\section{REFERENCES}

[1] Stats. Profiles of persons with disabilities in South Africa. Pretoria. Census 2011.

[2] White paper on the rights of a person with a disability. Government Gazette No. 39702. Accessed 9 March 2016.

[3] Ontario human rights commission strategic plan (2017-2022). Putting People and their Rights at the Centre: Building Human Rights Accountability. www.ohrc.on.ca Accessed 10 October 2019.

[4] D'Andrea W, Ford J, Stolbach B, Spinazzola J, Van der Kolk B. Understanding interpersonal trauma in children: Why we need a developmentally appropriate trauma diagnosis. American Journal of Orthopsychiatry 2012; 82 (20): 187-200. https://doi.org/10.1111/j.1939-0025.2012.01154.x

[5] Reed M, Curtis K. Experiences of students with visual impairments in Canadian Higher Education 2012; 106(Suppl 7): 414-425.

https://doi.org/10.1177/0145482X1210600704

[6] Rugoho T, Maphosa F. Challenges faced by women with disabilities in accessing sexual and reproductive health in Zimbabwe: The case of Chitungwiza town. African Journal of Disability 2017; 6: a252.

https://doi.org/10.4102/ajod.v6i0.252

[7] Research brief on disability and equality in South Africa (2013-2017). South African Human Rights Commission. www.sahrc.org.za. Accessed 14 December 2019.
[8] Tugli AK, Zungu LI, Ramakuela NJ, Goon DT, Anyanwu FC. Perceived challenges of serving students with disabilities in a historically disadvantaged tertiary institution, South Africa. African Journal for Physical, Health Education, Recreation and Dance 2013; Supplement 1-2: pp. 346-355.

[9] Taormina-Weiss $\mathrm{W}$. The costs of marginalizing people with disabilities. Disable World 2012. www.disabled-world.com Accessed 14 January 2020.

[10] Mutanga O. Students with disabilities' experience in South African higher education - A synthesis of literature. South African Journal of Higher Education 2017; 31 (1): 135-54. https://doi.org/10.20853/31-1-1596

[11] Plan International. Include Us! A study of disability among Plan International's sponsored children. UN-New York; 2012. URL: $\quad$ https://www.right-to-education.org/sites/right-toeducation.org/files/resourceattachments/Plan_Include_Us\%21_Report_2013_En.pdf

[12] Three formulations of the nexus requirements. Harvard Law Review 2013; 126(5): 1392-1413. https://harvardlawreview. org/wp-content/uploads/pdfs/vol126_reasonable_ accomodations_law.pdf

[13] Clarke D, Sawyer J. Girls, disabilities, and school education in the East Asia Pacific Region. Draft working discussion. United Nations Girls Education Initiative 2014 https://www.medbox.org/pdf/5e148832db60a2044c2d4713

[14] Herbert JT, Hong BSS, Byun S, Welsh W, Kurz CA, Atkin HA. Persistence and graduation of college students seeking disability support services. The Journal of Rehabilitation 2014; 80(1): 1-22.

[15] Taylor M, Turnbull $Y$, Bleasdale J, Francis H, Forsyth $H$. Transforming support for students with disabilities in UK Higher Education. Support for Learning 2017; 31(4): 367384.

https://doi.org/10.1111/1467-9604.12143

[16] Ingeno L. Online accessibility a faculty duty. Inside Higher Ed; June 24, 2013. http://www.insidehighered.com/news/ 2013/06/24/faculty-responsible-making-online-materialsaccessible-disabled-students. Accessed 14 September 2019

[17] Couzens D, Poed S, Kataoka M, Brandon A, Hartley J, Keen D. Support for students with hidden disabilities in universities: A case study. International Journal of Disability, Development, and Education 2015; 62(1): 24-41. https://doi.org/10.1080/1034912X.2014.984592

[18] Fleming AR, Oertle KM, Plotner AJ, Hakun JG. Influence of social factors on student satisfaction among college students with disabilities. Journal of College Student Development 2017; 58(2): 215-228. https://doi.org/10.1353/csd.2017.0016

[19] De las Santos SB, Kupenzynski L, Mundy M. Determining academic success in students with disabilities in higher education. International Journal of Higher Education 2019; 8(2): 16-35.

\section{https://doi.org/10.5430/ijhe.v8n2p16}

[20] Albert B. Disability KaR research project enabling disabled people to reduce poverty. The social model of disability, human rights, and development. Disability KaR Knowledge and Research 2004. www. disabilitykar.net Accessed 23 October 2019. URL: http://enil.eu/wp-content/uploads/2012/ 07/The-social-model-of-disability-human-rightsdevelopment_2004.pdf

\section{https://doi.org/10.6000/2292-2598.2021.09.06.3}

(C) 2021 Mukwevho and Gadisi; Licensee Lifescience Global.

This is an open access article licensed under the terms of the Creative Commons Attribution License (http://creativecommons.org/licenses/by/4.0/) which permits unrestricted use, distribution and reproduction in any medium, provided the work is properly cited. 